Article

\title{
SU-8 Composite Based "Lube-tape" for a Wide Range of Tribological Applications
}

\author{
Prabakaran Saravanan $^{1}{ }^{*}$, Nalam Satyanarayana ${ }^{1}$ and Sujeet K. Sinha ${ }^{2}$ \\ 1 Department of Mechanical Engineering, National University of Singapore, Singapore 117576; \\ E-Mail: elens@nus.edu.sg \\ 2 Department of Mechanical Engineering, Indian Institute of Technology, Kanpur 208016, U.P, \\ India; E-Mail: sujeet@iitk.ac.in \\ * Author to whom correspondence should be addressed; E-Mail: A0080599@ nus.edu.sg; \\ Tel./Fax: +65-6516-4693.
}

Received: 21 March 2014; in revised form: 1 May 2014 / Accepted: 8 May 2014 /

Published: 19 May 2014

\begin{abstract}
In a previous work, we have developed a perflouropolyether (PFPE) lubricant droplet-filled SU-8 composite which promotes bonding between the molecules of SU-8 and PFPE and provides excellent boundary lubrication. The SU-8 + PFPE composite has enhanced the wear durability of SU- 8 by more than four orders of magnitude. In this work, the same SU-8 + PFPE composite was used to fabricate a stand-alone laminate film called "Lube-tape". It has integrated two layers of approximately 90 microns thickness each; the top layer is made of SU-8 + PFPE composite and the bottom layer of pristine SU-8. Thus, a single tape can have drastically contrasting high friction and low friction properties on its two surfaces. The composite side has the initial coefficient of friction $\sim 7$ times lower and the wear life more than four orders of magnitude than those of the pristine SU-8 side. This lube tape can be used on any load bearing surface to improve the tribological performance by simply pasting the pristine SU-8 side onto the substrate.
\end{abstract}

Keywords: SU-8; PFPE; composite; polymer tribology; Lube-tape; chemical bonding

\section{Introduction}

SU-8 is a negative photo-resist polymer [1]. SU-8 consists of three basic components: (a) an EPONTM SU-8 epoxy resin; (b) a solvent such as gamma-butyrolactone (GBL); and (c) a photoacid 
generator such as triarylsulfonium salts. Each SU-8 molecule consists of an average of 8 epoxy groups (and hence the name SU-8). SU-8 is finding many applications in micromachines [2] and bio-MEMS as a structural material because of its UV-curing property, however, it suffers from the major drawbacks of high friction and low wear life. Hence, it cannot be used in a tribological application where the coefficient of friction is to be low and wear life to be high, unless SU-8 is modified suitably.

Very few works can be found in the literature on improving the tribology of SU-8. Jiguet et al. [3] have studied the effect of silica particle reinforcement of SU-8 and heat treatment of SU-8. The improvements in tribology from silica reinforcement and heat treatment are very marginal, but the heat treatment improved mechanical properties considerably. Among few studies by Singh et al. [4,5], notable is the "two-step surface modification" process, which uses the oxygen-plasma treatment of SU-8 surface, followed by coating of lubricant such as perfluoropolyether (PFPE). The tribological performance of SU-8 improved significantly by this method. Another study is on the chemical-modification of SU-8 surface by treating chemically with ethanolamine-sodium phosphate buffer, followed by a coating of PFPE lubricant. The wear-life was increased considerably in this case also, which was attributed to the end group bonding between PFPE and ethanolamine molecules.

PFPE has several superior properties such as high chemical and thermal stability, resistance to oxidation, low vapor pressure, self-replenishment property, hydrophobic nature, good lubricity and good adhesion with different substrates [6]. Therefore, it was used as a lubricant filler material in our recent study [7], where the SU-8 + PFPE composite has shown a significant reduction in the initial coefficient of friction and increased wear life by more than four orders of magnitude. It was postulated that SU-8 and PFPE molecules might undergo a chemical reaction and form an ether bond. Because of this reason, addition of PFPE, a lubricant, into SU-8 did not decrease the mechanical properties but rather there was an increase in the elastic modulus and hardness of SU-8 as a result of PFPE inclusion [7].

The Lube-tape is another application of the SU-8 + PFPE composite which consists of dual layers, $\sim 90 \mu \mathrm{m}$ each; top layer is SU-8 + PFPE and bottom one is pristine SU-8. The pristine SU-8 has high frictional property with high surface free energy; hence it can be easily stuck to the targeted surface. The top composite layer has low frictional and wear durability properties, so this surface can act as low friction surface protecting the substrate against wear. The PFPE concentration in the composite side of the tape was selected as $5 \mathrm{wt} \%$ and $10 \mathrm{wt} \%$, and then the tribological behavior was evaluated.

\section{Experimental Section}

\subsection{Materials and Sample Preparation}

Figure 1 shows a schematic of sample preparation procedure for making a "Lube-tape". Mylar ${ }^{\circledR}$ sheets were cut into $\sim 3 \mathrm{~cm} \times 3 \mathrm{~cm}$ pieces and were thoroughly cleaned with soapy water, distilled water and isopropyl alcohol (IPA), respectively, and finally dried with $\mathrm{N}_{2}$ gas. The cleaned pieces were then subjected to spin-coating immediately. The SU-8 grade used for the sample preparation was SU-8 2050. For the preparation of the "Lube-tape" films, SU-8 was spin-coated onto the Mylar ${ }^{\circledR}$ sheet wafer at an initial speed of $500 \mathrm{rpm}$ for a duration of $5 \mathrm{~s}$, followed by an increase in the spinning speed to $3000 \mathrm{rpm}$ for a duration of $60 \mathrm{~s}$ which results in SU-8 films with a thickness of $\sim 90$ microns. Thicknesses of the films were measured using WYKO NT1100 optical profiler (Vecco Instruments 
Inc., Plainview, NY, USA). The spin-coated SU-8 films were then subjected to pre-baking at a temperature of $65{ }^{\circ} \mathrm{C}$ for $4 \mathrm{~min}$, followed by at $95{ }^{\circ} \mathrm{C}$ for $9 \mathrm{~min}$. The pre-baked SU-8 films were then again subjected to spin-coating of SU8 + PFPE composite over the pre-baked SU8 film at an initial speed of $500 \mathrm{rpm}$ for a duration of $5 \mathrm{~s}$, followed by an increase in the spinning speed to $3000 \mathrm{rpm}$ for a duration of $60 \mathrm{~s}$ which resulted in SU-8 + PFPE film with a thickness of $\sim 90$ microns. The spin coated SU-8 + PFPE films over pristine SU8 films were then subjected to pre-baking at a temperature of $65{ }^{\circ} \mathrm{C}$ for $4 \mathrm{~min}$, followed by at $95{ }^{\circ} \mathrm{C}$ for $9 \mathrm{~min}$. Then, the spin-coated SU-8 + PFPE composite film along with the bare SU-8 film was subjected to UV (ultra-violet) rays (wavelength: $365 \mathrm{~nm}$ and power: $210 \mathrm{~mJ} / \mathrm{cm}^{2}$ ) for a duration of $30 \mathrm{~s}$. A post- UV exposure bake was carried out at a temperature of $65{ }^{\circ} \mathrm{C}$ for $1 \mathrm{~min}$, followed by at $95{ }^{\circ} \mathrm{C}$ for $7 \mathrm{~min}$. Finally, the "Lube-tape" film was peeled-off from the Mylar ${ }^{\circledR}$ sheet by mild heating. The peeled-off Lube-tapes were stored in desiccators till any further characterization.

Figure 1. Schematic illustrating the sample preparation procedure for SU-8 + PFPE based "Lube-tape".

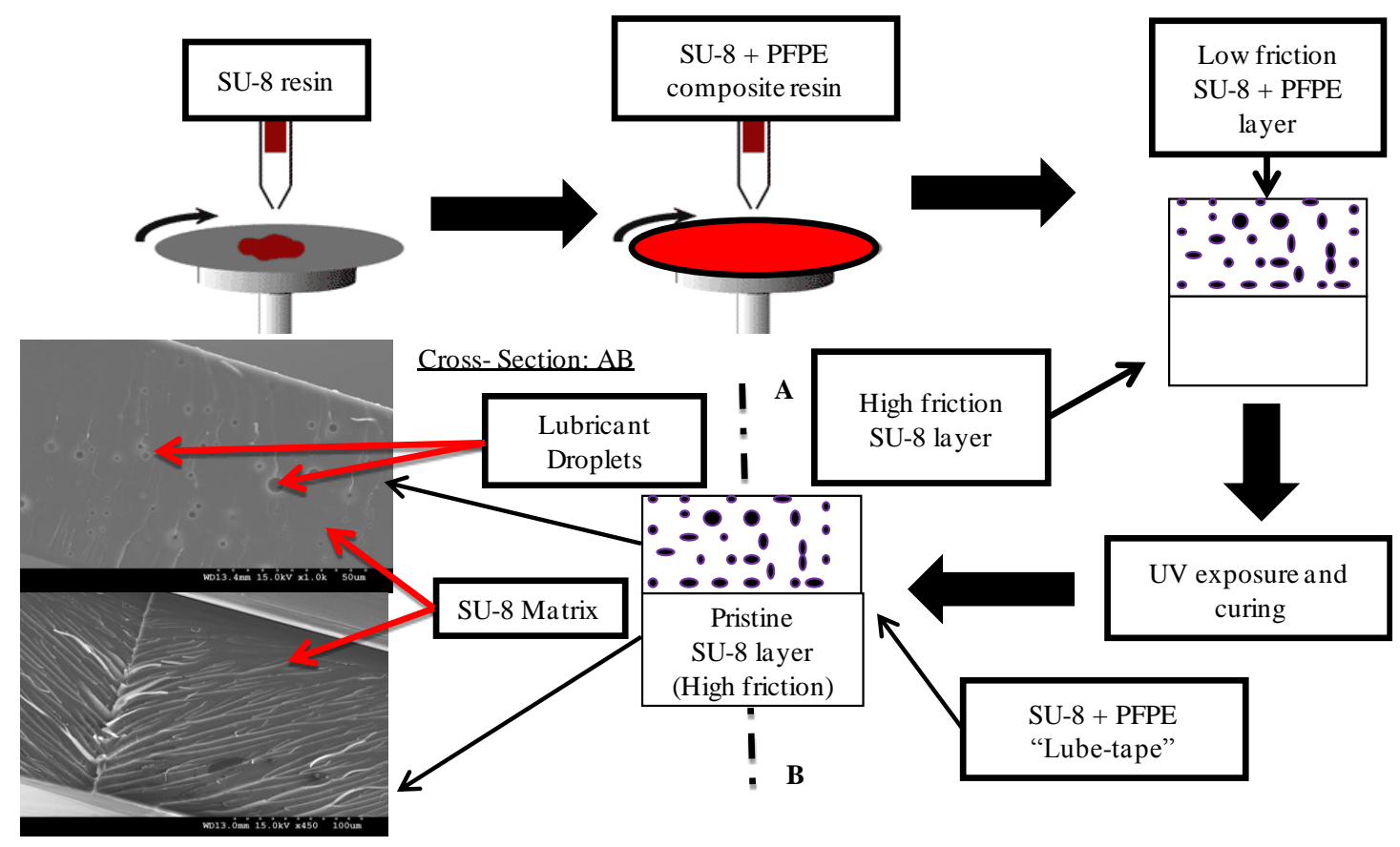

For the preparation of the SU-8 + PFPE composite layer, 5 wt $\%$ of lubricant was added to SU-8 (grade 2050) and then the composite materials were thoroughly mixed using sonicator for about $12 \mathrm{~h}$ before spin-coating. Sonication will break the lubricant droplets into small sizes $(<1 \mu \mathrm{m})$ possible against their intermolecular forces using sound waves.

The physical properties of Fomblin ${ }^{\circledR}$ Z-dol 4000 which was used in this work (obtained from Solvay Solexis, Singapore) are as follows: Density $=1.82 \mathrm{~g} / \mathrm{cm}^{3}$; Kinematic Viscosity $=18.2 \mathrm{cSt}$; Surface tension $=22 \mathrm{mN} / \mathrm{m}$; Molecular weight $=4000 \mathrm{~g} / \mathrm{mol}$, mono-dispersed. PFPE molecules have terminal-OH groups at their ends, and the chemical formula of PFPE is as follows (where p/q ratio is 2/3):

$$
\mathrm{HO}-\mathrm{CH}_{2}-\mathrm{CF}_{2}-\left(\mathrm{O}-\mathrm{CF}_{2}-\mathrm{CF}_{2}\right)_{\mathrm{p}}-\left(\mathrm{O}-\mathrm{CF}_{2}\right)_{\mathrm{q}}-\mathrm{O}-\mathrm{CF}_{2}-\mathrm{CH}_{2}-\mathrm{OH}
$$

H-galden, ZV60, obtained from Ausimont INC, is a solvent used to dissolve PFPE. 


\subsection{Surface Free Energy Calculations}

The surface free energy of both pristine SU-8 and SU-8 + PFPE composite sides were calculated using static water contact angles (WCAs), measured by VCA Optima Contact Angle System (AST Products Inc., Billerica, MA, USA). All measurements were performed in air at ambient temperature and relative humidity of $25{ }^{\circ} \mathrm{C}$ and $60 \%$, respectively. Owens-Wendt equation was used for the surface energy calculations and corresponding equation is shown below [8],

$$
\left(1+\cos \theta_{i}\right) \gamma_{i}=2\left(\sqrt{\gamma_{i}^{d} \gamma_{s}^{d}}+\sqrt{{\gamma_{i}^{p} \gamma_{s}^{p}}^{p}}\right)
$$

where $\theta_{i}$ is the contact angle, $\gamma_{i}{ }^{d}$ and $\gamma_{i}{ }^{p}$ are dispersive and polar surface tensions of liquids respectively, $\gamma_{s}{ }^{d}$ and $\gamma_{s}{ }^{p}$ are the dispersive and polar surface energies of the surface, respectively, to be calculated. In order to perform the surface energy calculation, a minimum of two polar and one non-polar liquid have to be used. Droplets of $0.5 \mu \mathrm{L}$ volume of water, ethanol, hexadecane and $n$-hexane were used for contact angle measurements. At least five replicate measurements, for three different samples, were carried out and an average value is reported in this paper. The variation in water contact angles at various locations of a sample was within $\pm 3^{\circ}$. The measurement error was within $\pm 1^{\circ}$.

\subsection{Tribological Characterization}

Tribological tests (friction and wear tests) were performed using UMT-2 (universal Micro Tribometer, CETR, Campbell, CA, USA) in a ball-on-disk setup. The typical number of sliding cycles $v s$. coefficient of friction $(\mathrm{CoF})$ plot is the outcome of the sliding tests, where $\mathrm{CoF}$ values are derived with respect to the corresponding sliding cycles. $\mathrm{Si}_{3} \mathrm{~N}_{4}$ balls of $4 \mathrm{~mm}$ diameter with a surface roughness of $5 \mathrm{~nm}$ were used as the counterface. All experiments were performed in air at room temperature $\left(23{ }^{\circ} \mathrm{C}\right)$ and at a relative humidity of approximately $60 \%$. From the sliding tests, an initial coefficient of friction $\left(\mu_{\mathrm{i}}\right)$ was noted as an average of the first twenty sliding cycles. The steady-state coefficient of friction $\left(\mu_{\mathrm{s}}\right)$ was measured as the average of all coefficients of friction from the point where the steady-state behavior (after the observation period of initial coefficient of friction) was observed until the end of the test or until the failure point, whichever was earlier [9].

The wear life for the tested conditions was taken as the number of sliding cycles after which the coefficient of friction exceeded 0.3 or a visible wear track was observed on the substrate with abnormally fluctuating friction values, whichever occurred earlier. For each composite, at least 3 tests were repeated and average data are reported.

It is to be noted that the sliding tests were carried out on both sides of stand-alone "Lube-tape" by just flipping over the "Lube-tape" from high friction (SU-8 side) side to low friction (SU-8 + PFPE) side. The two parts were integral to one single tape with equal thickness of 90 micron each. The cured "Lube-tape" was cut into 4 parts and one flat side was used to study the tribology of SU-8 side and the reverse was used to study the tribology of SU- $8+$ PFPE. Hence, the total thickness will be same irrespective of the side being tested and hence the stiffness of the specimen will also be the same. 


\subsection{FE-SEM Characterization}

The surface morphologies of the wear track and the cross-section of pristine SU- 8 and SU- 8 composite films were studied using Field Emission Scanning Electron Microscopy (FESEM) (FESEM S-4300, Hitachi High-Technologies Inc., Mississauga, ON, Canada). Prior to FESEM imaging, the samples were gold coated at $10 \mathrm{~mA}$ for $30 \mathrm{~s}$ using a JEOL, JFC-1200 Fine Coater (Joel Inc., Peabody, MA, USA). EDS attached to the FESEM was used to analyze the chemical elements of pristine SU-8 and SU-8 composites.

\section{Results and Discussion}

The SU-8 based "Lube-tape" films formed under the conditions provided in the experimental section have shown a total thickness of $\sim 180 \mu \mathrm{m}$. Figure 2 shows the low and high friction features of "Lube-tape" and descriptions about them.

Figure 2. Free standing SU-8 composite based "Lube-tape" (left image) showing the top view. A graphical illustration of the cross-section of the Lube-tape (right image) showing different friction behavior of top surface and bottom surface, respectively. The lubricant droplets range from few $\mathrm{nm}$ to $5 \mu \mathrm{m}$ (SEM images shown in subsequent figures can be referred for the morphology lubricant droplets inside SU-8 matrix).

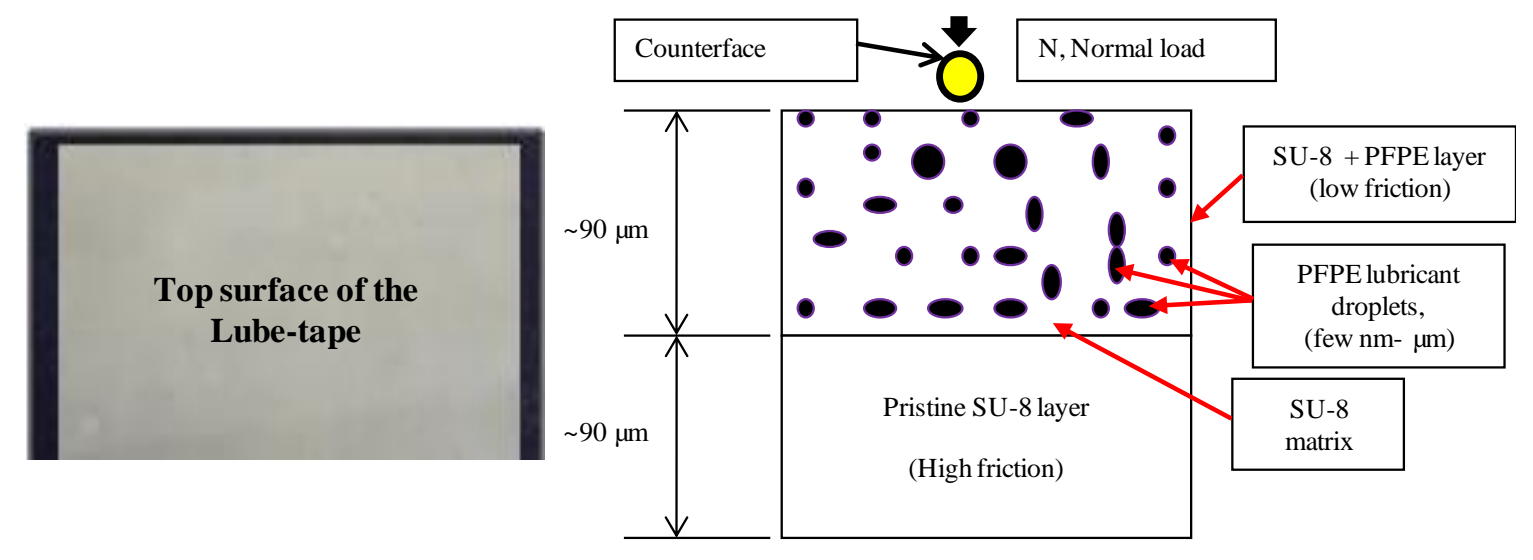

The top surface of Lube-tape is shown in left image of Figure 2, which is the low friction SU-8 + PFPE composite surface. The bottom layer is pristine SU-8 layer, which is the high friction layer and also can be easily stuck onto any surface.

\subsection{Surface Free Energy Calculations on Fresh Surface}

Surface free energy values of freshly spin-coated surfaces of pristine SU-8 and SU-8 + PFPE composite sides are shown in Table 1a. Figure 3 shows the distinction between the fresh surface and worn surface. Pristine SU-8 shows the highest surface free energy of $32.64 \mathrm{mN} / \mathrm{m}$, hence it offers greater adhesion and friction, whereas SU-8 + PFPE shows the surface free energy of $24.14 \mathrm{mN} / \mathrm{m}$. However, the pristine SU-8 shows the polar surface energy of $12 \mathrm{mN} / \mathrm{m}$, which is four times higher than that of SU-8 + PFPE. This high polar nature of pristine SU-8 makes the surface much more 
hydrophilic. Hence high polar component of the surface free energy may lead to high adhesion and friction [10].

Table 1. Polar, dispersive and total Surface energies of pristine SU-8 side and SU-8 + PFPE side of Lube-tape, respectively. (a) At fresh surfaces; (b) At worn surfaces (wear track).

\begin{tabular}{cccc}
\hline Composite Description & $\begin{array}{c}\text { Polar Surface } \\
\text { Energy (mN/m) }\end{array}$ & $\begin{array}{c}\text { Dispersive Surface } \\
\text { Energy (mN/m) }\end{array}$ & $\begin{array}{c}\text { Total Surface } \\
\text { Energy (mN/m) }\end{array}$ \\
\hline \multicolumn{4}{c}{ (a) Condition: On Fresh Surface } \\
\hline SU-8 & 11.44 & 21.2 & 32.64 \\
SU-8 + PFPE & 3.36 & 20.78 & 24.14 \\
\hline \multicolumn{4}{c}{ (b) Condition: On Worn Surface(Wear Track) } \\
\hline SU-8 & 26.1 & 23.38 & 49.48 \\
SU-8 + PFPE & 3.54 & 19.44 & 22.98 \\
\hline
\end{tabular}

Note: Standard error for all cases is $\pm 1.2 \mathrm{mN} / \mathrm{m}$.

Figure 3. Digital image shows the fresh surface and worn surface where the surface energy characterization was performed.

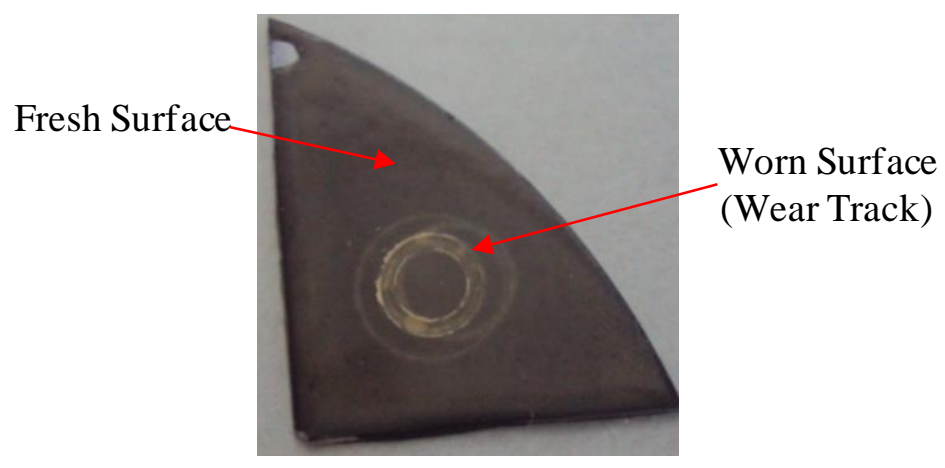

\subsection{Tribological Characterization}

Table 2 shows the initial coefficient of friction $\left(\mu_{i}\right)$, the steady-state coefficient of friction $\left(\mu_{\mathrm{s}}\right)$ and the wear life data for Lube-tape films (conducted at both sides i.e., high friction and low friction sides, respectively) with different PFPE concentrations and at different loads and rotational speeds, respectively. The tribological data summarized in Table 2 were obtained from typical coefficient of friction $(\mu)$ versus number of cycles $(\mathrm{N})$ plots as shown in Figure 4.

The tribological properties of $5 \mathrm{wt} \%$ Lube-tape, obtained at a normal load of $300 \mathrm{~g}$ and a rotational speed of $1000 \mathrm{rpm}$ will be discussed in this section as also shown in Table 2 (bottom) and Figure 4b. The pristine SU-8 side has shown high friction properties $\left(\mu_{\mathrm{i}}: \sim 0.56\right)$ and low wear life $(n \sim 10)$ when tested at a normal load of $300 \mathrm{~g}$ and at rotational speeds of $1000 \mathrm{rpm}$, respectively. Under the same loading conditions, SU-8 + PFPE side has shown very low coefficients of friction $\left(\mu_{\mathrm{i}}: 0.05\right.$ and $\left.\mu_{\mathrm{s}}: 0.12\right)$ and high wear life $(n>500,000)$. Therefore, the composite of SU-8 + PFPE side of the tape shows significant improvement in tribological properties (the $\mu_{\mathrm{i}}$ has been reduced by $\sim 8$ times and the wear life has been improved by $>250$ times) when compared with the properties of high friction side (pristine SU-8). The friction behavior of the pristine SU-8 side, tested at $300 \mathrm{~g}$ and $1000 \mathrm{rpm}$ is shown in Figure 4b. The observed trend is quite unusual as the COF drops from higher value of 0.6 to 0.4 and 
from 0.4 to 0.2 in two steps. The high friction SU-8 side started wearing-off right at the beginning and partially exposing the SU-8 + PFPE layer underneath. As the wear process progresses further, the pristine SU-8 is worn-off completely and the counterface ball touches the SU-8 + PFPE layer. At this stage the coefficient of friction drops to a value matching the values equivalent to SU-8 + PFPE side. Small difference is because of the presence of large amount of debris material when sliding is started from pure SU-8 side.

Table 2. Tribological test results of SU-8 Lube-tape (initial coefficient of friction $\left(\mu_{\mathrm{i}}\right)$, steady-state coefficient of friction $\left(\mu_{\mathrm{s}}\right)$ and wear life (number of sliding cycles)) of 10 and 5 wt $\%$ SU-8 + PFPE Lube-tapes, tested against $4 \mathrm{~mm}$ diameter $\mathrm{Si}_{3} \mathrm{~N}_{4}$ ball at different loads and sliding speeds. (Both sides of the Lube-tape were tested, as indicated).

\begin{tabular}{|c|c|c|c|}
\hline $\begin{array}{l}\text { Composite } \\
\text { Description }\end{array}$ & $\begin{array}{l}\text { Initial coefficient of } \\
\text { friction, } \operatorname{COF}\left(\boldsymbol{\mu}_{\mathrm{i}}\right)\end{array}$ & $\begin{array}{l}\text { Steady-state coefficient } \\
\text { of friction, } \operatorname{COF}\left(\mu_{\mathrm{s}}\right)\end{array}$ & $\begin{array}{c}\text { Wear Life } \\
\text { (Number of Cycles, } \mathbf{N})\end{array}$ \\
\hline \multicolumn{4}{|c|}{10 wt \% SU-8 + PFPE Free-standing Lube-tape Film/Test Parameter: 300 g, 2000 rpm $(0.4$ m/s $)$} \\
\hline $\begin{array}{l}\text { High Friction Side } \\
\text { (SU-8 alone) }\end{array}$ & 0.62 & - & $\sim 10$ \\
\hline Low friction Side & 0.08 & 0.19 & $\begin{array}{c}\text { Failed at } \\
700,000 \pm 5000 \text { cycles }\end{array}$ \\
\hline \multicolumn{4}{|c|}{5 wt \% SU-8 + PFPE Free Standing Lube-tape Film/Test Parameter: $300 \mathrm{~g}, 1000 \mathrm{rpm}(0.2 \mathrm{~m} / \mathrm{s})$} \\
\hline $\begin{array}{l}\text { High Friction Side } \\
\text { (SU-8 alone) }\end{array}$ & 0.56 & - & $\sim 10$ \\
\hline Low friction Side & 0.05 & 0.12 & $>500,000 \pm 5000$ cycles \\
\hline
\end{tabular}

Note: Steady-state values are not mentioned for the SU-8 sides (high-friction) that did not contain PFPE as those sides failed right in the first sliding cycle according to the wear-failure criteria proposed in this study.

Figure 4. Typical coefficient of friction versus number of cycles plot for different wt $\%$ SU-8 + PFPE composite based Lube-tape film obtained from the ball-on-disk sliding tests against $4 \mathrm{~mm}$ diameter $\mathrm{Si}_{3} \mathrm{~N}_{4}$ ball at a normal load of $300 \mathrm{~g}$ and a sliding speed of $2000 \mathrm{rpm}$. (a) $10 \mathrm{wt} \%$; (b) $5 \mathrm{wt} \%$.

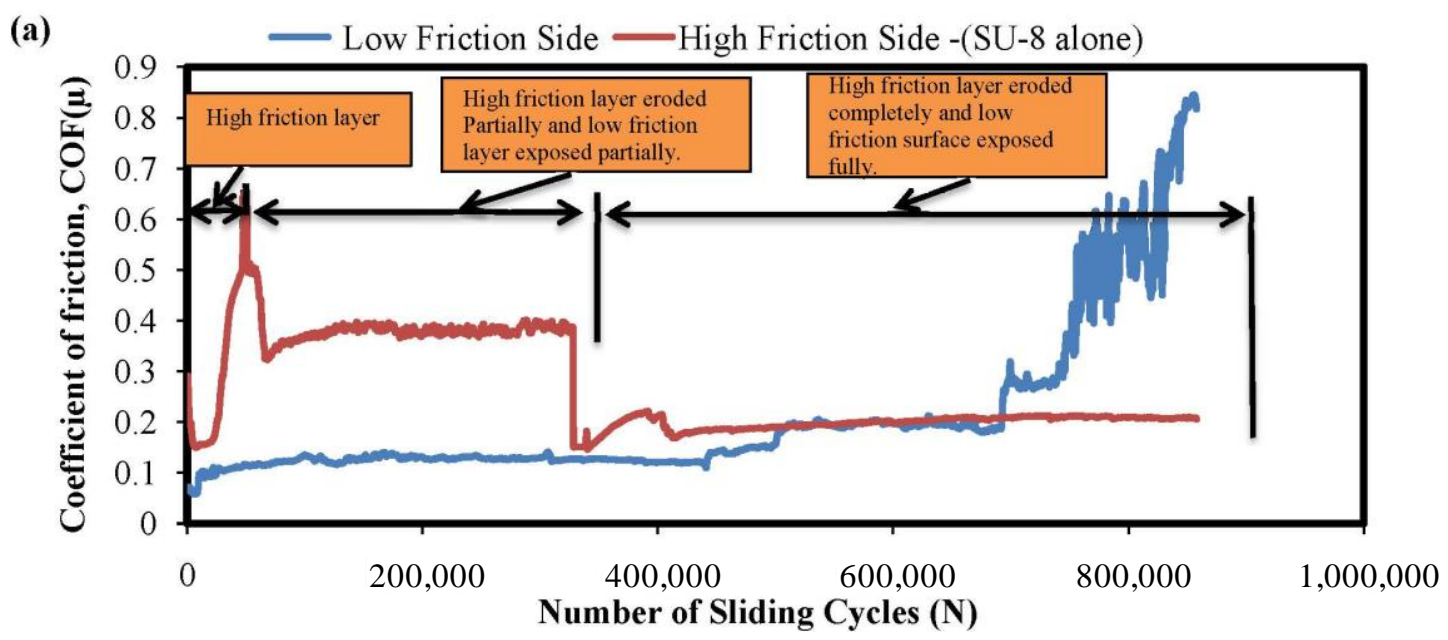


Figure 4. Cont.

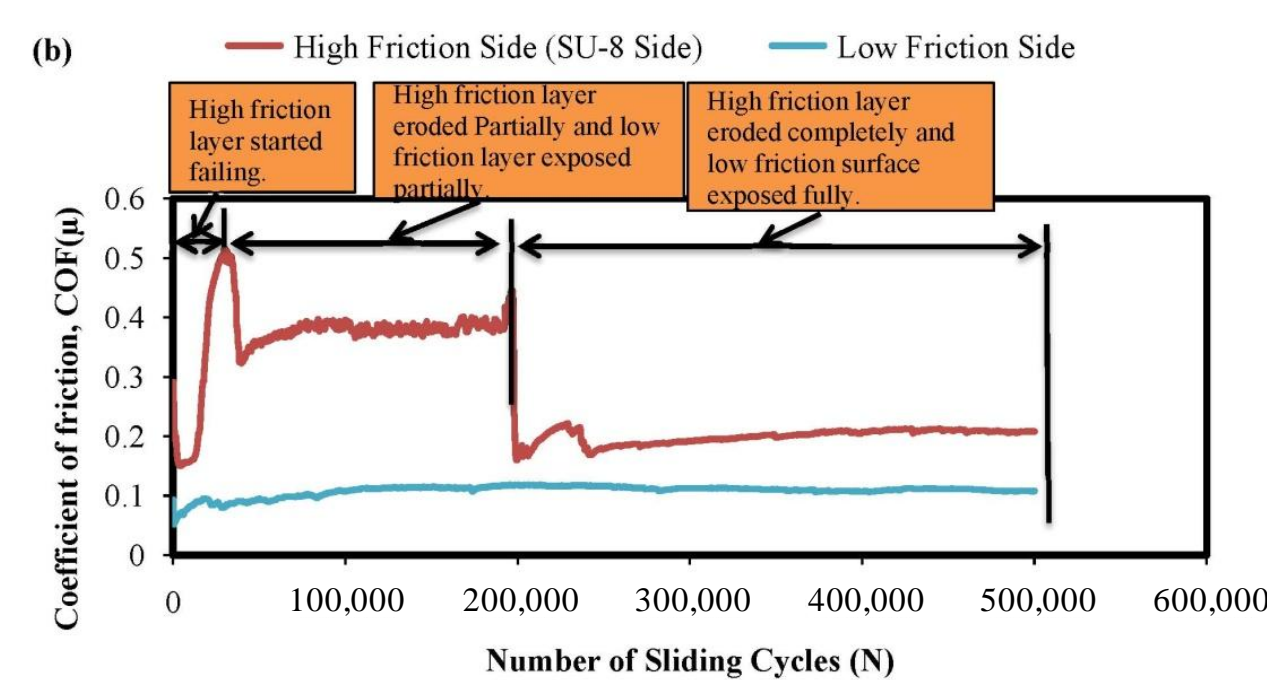

The high friction side (pristine SU-8 side) of the tape can be used to adhere to the surface of interest whereas the SU8 + PFPE layer will be exposed against the moving counterface material and can reduce the friction and increase the wear life. The PFPE concentration in the composites was increased from $5 \mathrm{wt} \%$ to $10 \mathrm{wt} \%$ and then the tribological behavior was evaluated at a normal load of $300 \mathrm{~g}$ and sliding speed of $2000 \mathrm{rpm}$. An increase of PFPE concentration from $5 \mathrm{wt} \%$ to $10 \mathrm{wt} \%$ has shown an improvement in the wear lives by $30 \%-40 \%$ at the identical speed and load configuration. Therefore, the concentration of the PFPE has to be optimized depending on the application requirements and the operating conditions of the Lube-tape once it is placed in the application.

\subsection{Surface Free Energy Calculations on Worn Surface}

Surface free energy measurements were performed on wear tracks of pristine SU-8 (10,000 cycles) and SU-8 + PFPE composite (after enduring 700,000 sliding cycles) sides of Lube-tape tested at a normal load of $300 \mathrm{~g}$ and sliding speed of $2000 \mathrm{rpm}$, as shown in Table 1b. Pristine SU-8 shows the highest surface energy of $49.48 \mathrm{mN} / \mathrm{m}$. It also shows the highest polar contribution of $26.1 \mathrm{mN} / \mathrm{m}$, which is $15 \mathrm{mN} / \mathrm{m}$ more than that of the fresh surface, indicating that unsatisfied broken bonds make it highly hydrophilic [10].

However, SU-8 + PFPE wear track shows very low surface free energy of $22.98 \mathrm{mN} / \mathrm{m}$, which is $\sim 2 \mathrm{mN} / \mathrm{m}$ less than that of the fresh surface, suggesting proper surface coverage by PFPE lubricant. It also indicates that the entire wear track is very well protected by thin film PFPE lubricant even after sliding for $\sim 700,000$ cycles. The polar surface energy of SU-8 and SU-8 + PFPE is $\sim 27$ and $\sim 4 \mathrm{mN} / \mathrm{m}$, respectively, at wear track conditions and it shows that SU-8 is more hydrophilic, offers high friction.

\subsection{Boundary Layer Lubrication}

Figure 5 shows SEM cross-sectional images of pristine SU-8 and SU-8 composite films. It is necessary to find the source of lubrication for the prolonged wear life of SU-8 + PFPE composites over pristine SU-8. Physical boundary layer lubrication was also found responsible along with chemical bonding between SU-8 and PFPE molecules. Before curing and UV exposure, the composite resin is in 
the gluey state, where the SU-8 matrix has lubricant (PFPE) droplets of sizes ranging from few nm to $5 \mu \mathrm{m}$ dispersed throughout its matrix. After UV exposure and curing, the SU-8 undergoes cross-linking and becomes solid. As the lubricant remains unaffected by the UV radiation, the droplets remain trapped in liquid form inside the solid SU-8 bulk. This trapped lubricant in tiny cavities gives an advantage of storing lubricants for self-regeneration and lubrication. The sectioned images are the measure of the lubricant dispersion and agglomeration within the composites. However, pristine SU-8 (Figure 5a) shows plain surface without any surface feature except some rough surface ridges, which is due to brittle nature of SU-8. SU-8 + PFPE (Figure 5b) shows uniformly dispersed round shaped droplets in greater number all across the film. Once the lubricant layer over the surface is worn away with counterface sliding, the lubricant droplets beneath the worn surface is released which forms the boundary layer to reduce the friction and wear and the same cycle repeats till the complete wear of the composite. This model also emphasizes that the tribological performance of composites depends on the uniform dispersion of lubricants and bonding of the lubricants with the surface. Hence, the effect of dispersion and bonding of the lubricant is vital in the wear durability of the SU-8 + PFPE composites.

Figure 5. SEM cross-sectional images of $\sim 90 \mu \mathrm{m}$ thick Lube-tape layers; (a) Pristine SU-8 layer; (b) 5 wt \% SU-8 + PFPE composite layer.
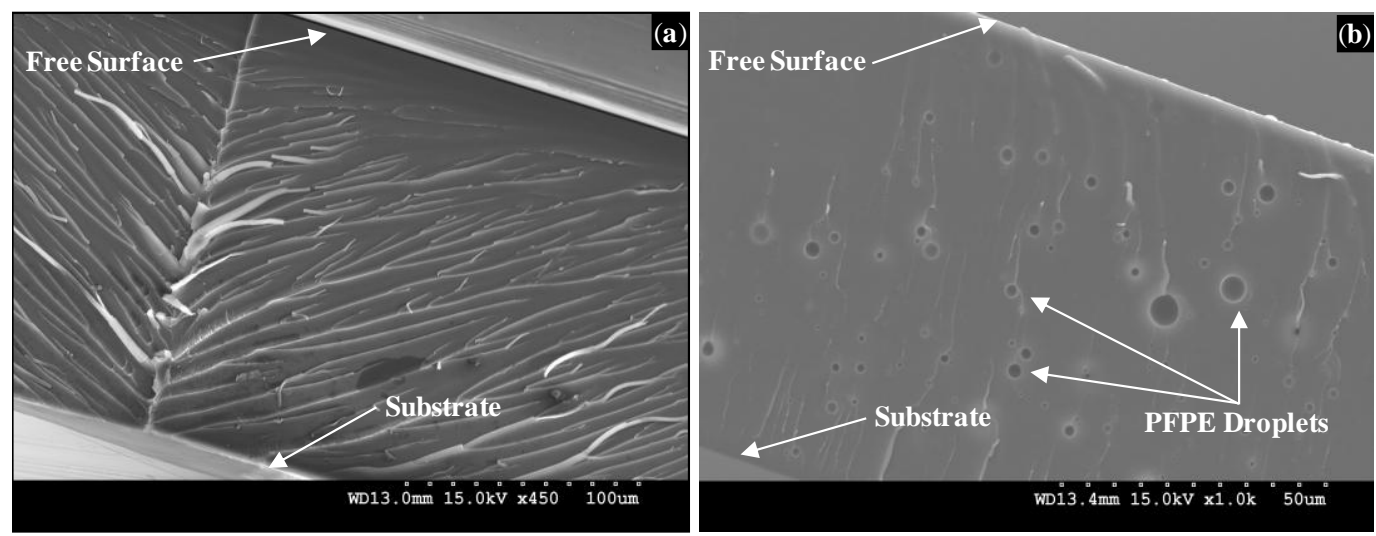

The significant improvement in tribological properties of SU-8 by the addition of PFPE can be attributed to the possible ether bond formation between the SU-8 and PFPE molecules $[11,12]$. The possible etherification reaction is depicted in Equation (2). It is postulated that the $-\mathrm{OH}$ terminal groups in the PFPE polymer and the carbocations $\left(\mathrm{C}^{+}\right)$in the SU-8 polymer (epoxide ring) undergo the reaction, which breaks the existing bond and forms new linkage through ether bonds.

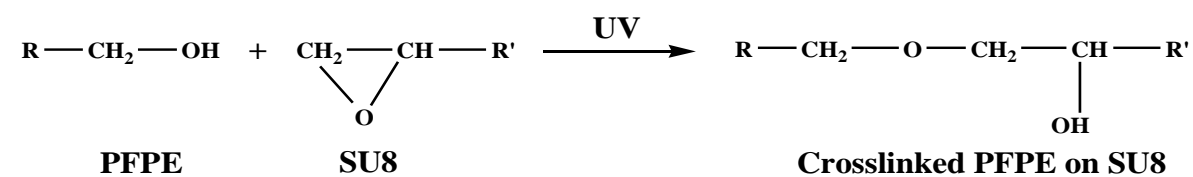

Few others have demonstrated the UV initiated graft polymerization of various polymers on SU-8 surface. Water-soluble monomers and other polymers like poly(acrylic acid) have been covalently grafted to SU-8 using UV-mediated grafting and also, chemically micro-patterned [13]. Under controlled conditions, the remainder photo acid generator triarylsulfonium hexafluoroantimonate works as a photo initiator and generates free radicals such as $\mathrm{C}-\mathrm{OO}, \mathrm{C}-\mathrm{O},-\mathrm{COOH}$ [13]. These evidences can be found in the literature [14-16]. The surface free energy calculation, tribological 
characterization and SEM images indicate the possibility of chemical reaction. It was thoroughly investigated and confirmed in our prior works [7,9].

\subsection{Optical Micrographs of Worn Surfaces}

Table 3 shows the optical micrographs of $10 \mathrm{wt} \%$ SU-8 + PFPE free standing Lube-tape film, tested on pristine SU-8 and SU-8 + PFPE sides at a normal load of $300 \mathrm{~g}$ and a sliding speed of $2000 \mathrm{rpm}$. Row 1 in Table 3 shows the counterface ball immediately after the sliding test, counterface ball after cleaning with a solvent and the optical micrographs of the wear track (worn surface) of SU-8 side, respectively. Physical observation of the counterface ball before and after cleaning will reveal information about the amount of material transfer onto the counterface ball, mode of wear and damages caused to the counterface ball. The pristine SU-8 surface side shows severe wear with wide and deep wear track and loss of material too. The counterface ball also shows thick layer of material with some damages to the counterface ball. The counterface ball also shows distinct wear after cleaning with acetone. These images qualitatively support the tribological behavior mentioned in preceding sections. Row 2 in Table 3 shows the counterface ball, counterface ball after cleaning with the solvent and the micrographs of wear track of SU-8 + PFPE side, respectively. SU-8 + PFPE shows very mild wear track with less material removal and the presence of lubricant droplets on the counterface can also be witnessed. There is very less material transfer onto the counterface ball, which confirms less chance of adhesive wear and no wear debris are accumulated in and around the wear track. It is necessary to analyze the contents of the transferred material, whether it is SU-8 or PFPE film, therefore, the counterface ball was washed with PFPE solvent H-Gladen which washed away $\sim 80 \%$ (in terms of surface area) of the transfer materialand left only $\sim 20 \%$ which may be SU-8, which could be cleaned with acetone. These optical micrographs indeed confirm that SU-8 + PFPE side is highly resistant against friction and wear. They also supported the mechanisms explained in earlier sections.

Table 3. Optical micrographs of counterface balls surface after sliding tests, tested counterface balls after cleaning with solvents and worn surfaces, for both SU-8 side (at 10,000 cycles) and SU-8 + PFPE side of Lube-tape (at 700,000 cycles), respectively. The length of the scale bar is $100 \mu \mathrm{m}$ in all images.

\begin{tabular}{|c|c|c|c|}
\hline Composite Description & Counterface ball Image & $\begin{array}{c}\text { Counterface ball Image } \\
\text { after Cleaning }\end{array}$ & Worn Surface Image \\
\hline \multicolumn{4}{|c|}{10 wt \% SU-8 + PFPE Free Standing Lube-tape Film/Test Parameters: $300 \mathrm{~g}$ and 2000 rpm } \\
\hline SU-8 Side (High Friction) & & & \\
\hline $\begin{array}{l}\text { SU-8 + PFPE Side } \\
\text { (Low Friction Side) }\end{array}$ & & & \\
\hline
\end{tabular}




\section{Conclusions}

Overall, few major conclusions are drawn from this work. We have conceived a novel idea of adding liquid lubricant fillers to SU-8 polymer to improve its tribological performance. Adding PFPE to SU-8, formed SU-8 + PFPE based Lube-tape which has reduced the initial coefficient of friction $\left(\mu_{\mathrm{i}}\right)$ by $\sim 7$ times and enhanced wear life by four orders of magnitude at all lubricant concentrations. The cross-sectional SEM images confirm the entrapment of PFPE droplets and formation of boundary layer lubrication using the trapped lubricant in the composite side. The pristine SU-8 side will ensure strong bonding with the surface to be protected and the SU-8 + PFPE composite side will work for reducing friction and wear. This novel use of SU-8 composite for reducing the coefficient of friction and protecting any surface from wear would find many tribological applications.

\section{Acknowledgments}

This research is supported by the Singapore National Research Foundation under its CRP (Competitive Research Program) funding (Award Number: NRF-CRP 2-2007-04). The views expressed herein are those of the authors and are not necessarily those of the Singapore National Research Foundation.

\section{Author Contributions}

P. Saravanan, N. Satyanarayana and S.K. Sinha planned the experiments and P. Saravanan has performed most of the experiments. All authors have analyzed the data. P. Saravanan has written the main manuscript and prepared the figures and tables. All authors reviewed the manuscript.

\section{Conflicts of Interest}

The authors declare no conflict of interest.

\section{References}

1. Gelorme, J.D.; Cox, R.J.; Gutierrez, S.A.R. Photoresist Composition and Printed Circuit Boards and Packages Made Herewith. U.S. Patent 4,882,245, 21 November 1989.

2. Abgrall, P.; Conedera, V.; Camon, H.; Gue, A.-M.; Nguyen, N.T. SU-8 as a structural material for labs-on-chips and microelectromechanical systems. Electrophoresis 2007, 28, 4539-4551.

3. Jiguet, S.; Judelewicz, M.; Mischler, S.; Bertch, A.; Renaud, P. Effect of filler behavior on composite SU8 photoresist for moving micro-parts. Microelectron. Eng. 2006, 83, 1273-1276.

4. Singh, R.A.; Satyanarayana, N.; Kustandi, T.S.; Sinha, S.K. Tribo-functionalizing Si and SU8 materials by surface modification for application in MEMS/NEMS actuator-based devices. J. Phys. D Appl. Phys. 2011, 44, 015301; doi:10.1088/0022-3727/44/1/015301.

5. Singh, R.A.; Satyanarayana, N.; Sinha, S.K. Surface chemical modification for exceptional wear life of MEMS materials. AIP Adv. 2011, 1, 042141; doi:10.1063/1.3662096.

6. Bhushan, B. Nanoscale Boundary Lubrication Studies. In Springer Handbook of Nanotechnology, 3rd ed.; Bhushan, B., Ed.; Springer: Berlin/Heidelberg, Germany, 2010; pp. 1347-1396. 
7. Prabakaran, S.; Satyanarayana, N.; Sinha, S.K. Self-lubricating SU-8 nano-composites for microelectromechanical systems applications. Tribol. Lett. 2013, 49, 169-178.

8. Loeb, G.I.; Schrader, M.E. Modern Approaches to Wettability: Theory and Applications; Springer, New York, NY, USA, 1992; pp. 1-27.

9. Prabakaran, S.; Satyanarayana, N.; Sinha, S.K. Wear durability study on self-lubricating SU-8 composites with perfluoropolyther, multiply-alkylated cyclopentane and base oil as the fillers. Tribol. Int. 2013, 64, 103-115.

10. Minn, M.; Sinha, S.K. The frictional behavior of UHMWPE films with different surface energies at low normal loads. Wear 2010, 268, 1030-1036.

11. Tanaka, Y.; Kakiuchi, H. Study of epoxy compounds. Part VI. Curing reactions of epoxy resin and acid anhydride with amine, acid, alcohol, and phenol as catalysts. J. Polym. Sci. Part A 1964, 2, 3405-3430.

12. Constantin, F.; Fenouillot, F.; Pascault, J.-P.; Williams, R.J.J. Post-crosslinkable blends: Reactions between a linear poly (hydroxyl-amino ether) and a diepoxy. Macromol. Mater. Eng. 2004, 289, 1027-1032.

13. Wang, Y.; Bachman, M.; Sims, C.E.; Li, G.P.; Allbritton, N.L. Simple photografting method tochemically modify and micropattern the surface of SU-8 photoresist. Langmuir 2006, 22, 2719-2725.

14. Blagoi, G.; Keller, S.; Persson, F.; Boisen, A.; Jakobsen, M.H. Photochemical modification and patterning of SU-8 using anthraquinone photolinkers. Langmuir 2008, 24, 9929-9932.

15. Chan, C.M. Polymer Surface Modification and Characterization; Hanser Gardner Publications: Cincinnati, OH, USA, 1994.

16. Garbassi, F.; Morra, M.; Occhiello, E. Polymer Surfaces, 2nd ed.; John Wiley and Sons: New York, NY, USA, 1988.

(C) 2014 by the authors; licensee MDPI, Basel, Switzerland. This article is an open access article distributed under the terms and conditions of the Creative Commons Attribution license (http://creativecommons.org/licenses/by/3.0/). 